\title{
The anti-apoptotic and prognostic value of fibroblast growth factor 9 in gastric cancer
}

\author{
Chuanli Ren ${ }^{1,6}$, Hui Chen ${ }^{2}$, Chongxu Han ${ }^{1}$, Deyuan Fu ${ }^{3}$, Fuan Wang ${ }^{4}$, Daxin Wang ${ }^{1}$, \\ Li Ma ${ }^{5}$, Lin Zhou ${ }^{1}$, Dongsheng Han ${ }^{1}$ \\ ${ }^{1}$ Clinical Medical Testing Laboratory, Northern Jiangsu People's Hospital and Clinical Medical College of Yangzhou University, \\ Yangzhou, China \\ ${ }^{2}$ Geriatric Medicine, Northern Jiangsu People's Hospital and Clinical Medical College of Yangzhou University, Yangzhou, China \\ ${ }^{3}$ Breast Oncology Surgery, Northern Jiangsu People's Hospital and Clinical Medical College of Yangzhou University, \\ Yangzhou, China \\ ${ }^{4}$ Departments of Interventional Radiography, Northern Jiangsu People's Hospital and Clinical Medical College of Yangzhou \\ University, Yangzhou, China \\ ${ }^{5}$ Lab of hematology, Northern Jiangsu People's Hospital and Clinical Medical College of Yangzhou University, Yangzhou, China \\ ${ }^{6}$ Department of Epidemiology and Biostatistics, Ministry of Education (MOE) Key Laboratory of Modern Toxicology, School of \\ Public Health, Nanjing Medical University, Nanjing, China
}

Correspondence to: Chuanli Ren, e-mail: renchl@163.com

Keywords: gastric cancer, FGF9, apoptosis, prognosis

Received: October 10, $2015 \quad$ Accepted: March 02, $2016 \quad$ Published: March 17, 2016

\section{ABSTRACT}

Fibroblast growth factor (FGF) 9 is a member of the FGF family, which involves in carcinogenesis in some solid tumours. However, its biological and prognostic significance in gastric cancer (GC) is unclear. We examined FGF9 expression in 180 GC and corresponding non-tumorous gastric tissue samples by immunohistochemistry and evaluated its role in predicting tumour prognosis. Knockdown of FGF9 by siRNA inhibited cell growth and induced apoptosis in GC cell lines. Fifty of the $180 \mathrm{GC}$ specimens $(\mathbf{2 7 . 8 \% )}$ had high FGF9 protein expression, whereas decreased or unchanged expression was observed in 130 cases $(72.2 \%)$. High FGF9 expression was a significant predictor of poor survival ( 28.1 vs. 55.8 months, $P<0.001$ ). After stratification according to AJCC stage, FGF9 remained a significant predictor of shorter survival in stage II (30.6 vs. 64.9 months, $P<0.001)$ and stage III GC ( 29.7 vs. 58.9 months, $P<0.001)$. Multivariate and univariate analysis showed that higher expression of FGF9 can be used as a predictor for poor prognosis (HR, 2.95; 95\% CI, 1.97-4.41; $P<0.001$; and $H R, 2.94 ; 95 \% C I$, 2.01-4.31; $P<0.001$, respectively). FGF9 may provide the anti-apoptotic function and be useful as a novel independent marker for evaluating GC prognosis

\section{INTRODUCTION}

Gastric cancer (GC) is currently the fourth most common cancer and the second highest cause of cancerrelated mortality worldwide, accounting for an estimated 989,000 new cases and 738,000 deaths in 2008 [1]. However, nearly half the global GC incidence $(464,000)$ and deaths $(352,000)$ occur in China [1]. Gastric carcinogenesis is a multistep and multifactorial process, and identification of the subtypes of GC will provide a roadmap for patient stratification and development of targeted therapies $[2,3]$. Studies have shown that different molecular or protein expression profiles in
GC may have different prognoses [4]. Four molecular subtypes of $\mathrm{GC}$ were recently linked to distinct patterns of molecular alterations, disease progression and prognosis by gene expression data analysis ${ }^{3}$. However, the precise mechanisms underlying gastric carcinogenesis and prognosis remain unclear.

The fibroblast growth factor (FGF) family comprises 23 family members with important functions in embryonic development, tissue repair, tumourigenesis and other processes $[5,6]$. Among the FGFs, only 18 are ligands for FGF receptors (FGFRs), and these ligands bind FGFRs to induce downstream signalling. Binding of FGF to FGFR leads to a conformational shift in the FGFR structure, 
resulting in intermolecular transphosphorylation of the intracellular tyrosine kinase domain and carboxy-terminal tail of the receptor. Subsequent downstream signalling occurs through four main pathways: the RAS-RAFMAP kinase pathway, the PI3K-AKT pathway, the signal transducer and activator of transcription pathway, and the phospholipase pathway $[5,7,8]$. Notably, FGFR2 is preferentially amplified and overexpressed in the diffuse type of GC [9]. Several studies have linked dysregulated FGF9 in various cancers. High expression of FGF9 in nonsmall cell lung cancer was identified as a novel unfavourable prognostic indicator [10]. Furthermore, a previous study showed that miR-26a functions as a tumour suppressor in GC development and progression by targeting FGF9 [11].

However, the function of FGF9 expression on the prognosis of GC patients has not been fully elucidated. The purpose of this study was to examine the effects of FGF9 on the growth and apoptosis of GC cells and to evaluate the correlation between FGF9 expression and prognosis in a Chinese population of GC patients.

\section{RESULTS}

\section{Knocking down FGF9 inhibits growth and induces apoptosis in GC cells}

To first examine the function of FGF9 in GC cells, FGF9 siRNA or control siRNA were transfected into two gastric cancer cell lines, MGC-803 and SGC-7901, and the effects on cell growth and apoptosis were evaluated. Cell growth and colony formation experiments showed that knockdown of FGF9 inhibited cell growth in both gastric cancer cell lines compared with control siRNA transfections $(P<0.01)$ (Figure 1A, 1B, 1C). DAPI staining and flow
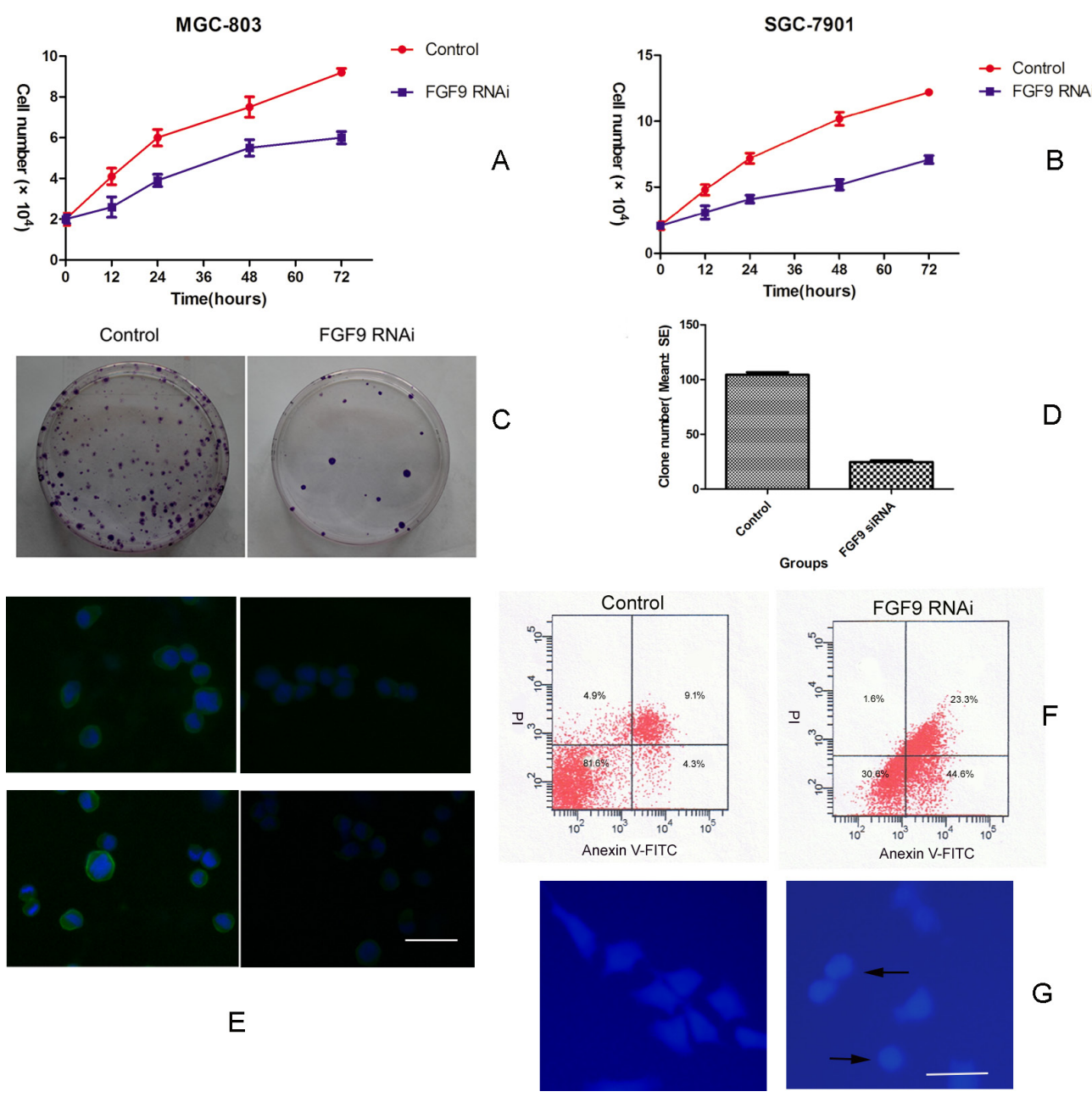

Figure 1: Downregulation of FGF9 by siRNA in GC cells inhibits cell growth and induces apoptosis. Growth of MGC803 A. and SGC-7901 cells B. transfected with FGF9 siRNA or control. MGC-803 cells transfected with FGF9 siRNA or control were analysed by colony formation assay $\mathbf{C}$. MGC-803 cells transfected with FGF9 siRNA or control were analysed by a histogram $(* P<0.001)$ D. MGC-803(upper layer) and SGC-7901 (below layer) cells were transfected with FGF9 siRNA (right figure) or control (left figure) and the expression of FGF9 was detected by immunofluorescence staining E. MGC-803 cells were transfected with FGF9 siRNA or control and apoptotic cells were evaluated by Annexin V-FITC and PI staining and FACS F. Apoptotic morphological analysis of MGC-803 cells transfected with FGF9 siRNA or control by DAPI staining G. All data are presented as mean \pm s.e.m from at least three separate experiments. 
cytometry analysis showed that knockdown of FGF9 induced apoptosis in gastric cancer cells compared with controls (Figure 1D, 1F). Immunofluorescence staining showed that MGC-803 (Figure 1E) and SGC-7901 (Figure not shown) were overexpression of FGF9. After the tranfection of FGF9 for 24 hours, the expression of FGF9 was decreased obviously (Figure 1E).

Together these results demonstrate that knocking down FGF9 inhibits cell growth and enhances apoptosis in $\mathrm{GC}$ cell lines.

\section{Aberrant expression of FGF9 in GC and paracancerous tissues}

Next we examined the expression of FGF9 in 180 $\mathrm{GC}$ and corresponding non-tumourous gastric tissue samples by immunohistochemistry staining. In normal paracancerous tissues, FGF9 was mainly located in the cytoplasm of the cells (Figure 2). Among the 180 total GC samples, FGF9 expression was decreased or unchanged in $72.2 \%$ of the GC cases (130/180) and increased in $27.8 \%$ (50/180) compared with the normal paracancerous tissues.

\section{Relationship between FGF9 expression and clinicopathological features in GC}

Next we examined the relationships between FGF9 expression and clinicopathological characteristics of

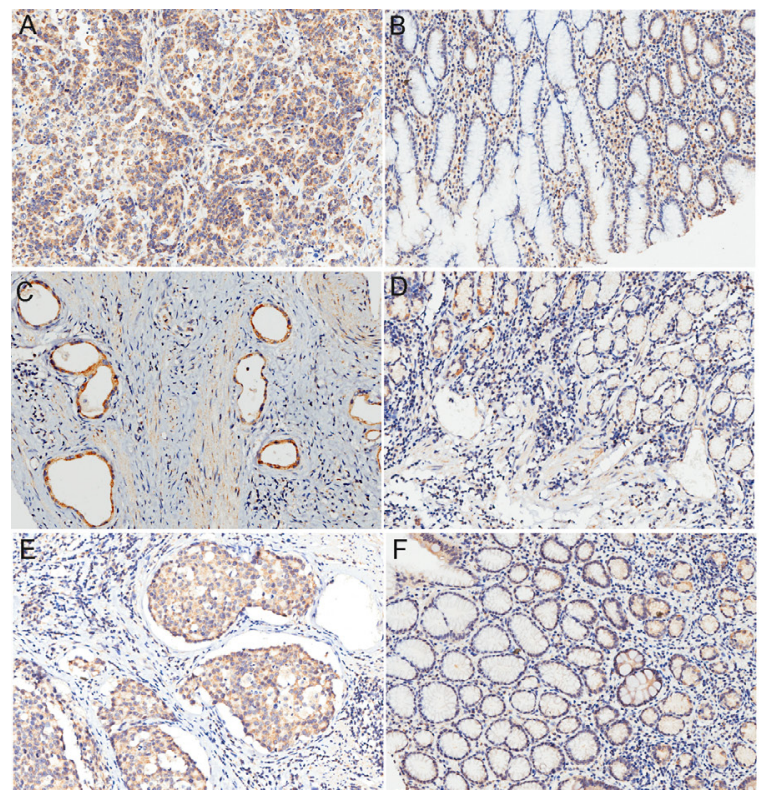

GC patients (listed in Table 1). We observed a tendency between age of patients with low/unchanged levels of FGF9 expression and patients with high expression $\left(\chi^{2}=5.634, P=0.018\right)$, but no significant correlations were found between FGF9 expression level and other clinicopathological variables, including sex, tumour site, TNM stage, tumour size, nodal status, distant metastasis and depth of tumour invasion (Table 2).

\section{Survival analysis}

The median overall survival (OS) in the study cohort was 41 months, and the longest was 98 months. KaplanMeier analysis demonstrated that high expression of FGF9, stage of disease, tumour status, node status, tumour size, and distant metastasis were significant negative prognostic predictors for OS in patients with GC $(P<0.001, P<$ $0.001, P=0.008, P<0.001, P=0.001$, and $P=0.005$, respectively). Other clinicopathological characteristics, including age, sex, and location, were not significantly associated with prognosis. Only 14 patients with distant metastases were included in the study, which may explain why the prognostic significance of distant metastasis was not as obvious as expected $(P=0.005$, Table 3$)$.

Higher expression of FGF9 $(n=49)$ remained a significant predictor of poor survival compared with lower expression of FGF9 ( $\mathrm{n}=114)$ (28.1 months vs. 55.8 months, $P<0.001)$. After stratification according

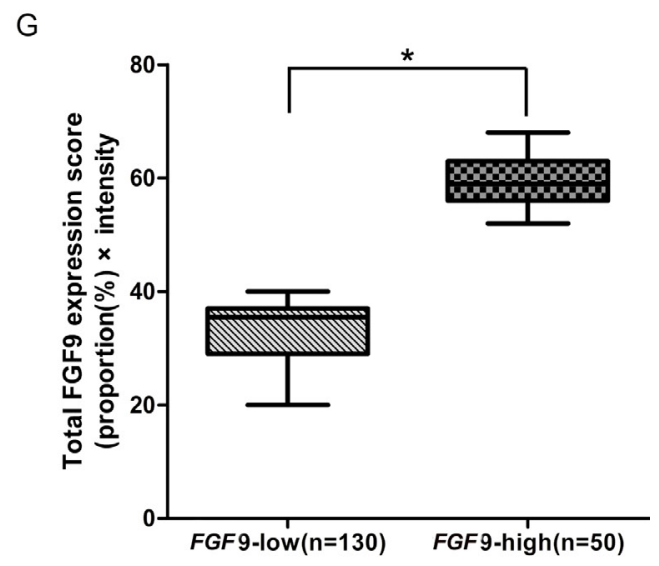

Figure 2: Immunohistochemical analysis of FGF9 expression and survival curves in patients with GC according to FGF9 levels. A. High FGF9 expression in gastric adenocarcinoma and low expression in corresponding non-cancerous gastric tissues $\mathbf{B}$. High FGF9 expression in gastric adenocarcinoma, part of signet-ring cell carcinom and low expression in corresponding non-cancerous gastric tissues C. and low FGF9 expression in corresponding non-cancerous gastric tissues D. High FGF9 expression in gastric gastric tubular adenocarcinom E. and low FGF9 expression in corresponding non-cancerous tissues F. The total FGF9 expression score was calculated by multiplying the proportion (\%) of cells expressing FGF9 with the intensity score described in Methods. The thick line indicates the median score in each group $\mathbf{G} . * P<0.001$, FGF9-low group vs. FGF9-high group (Mann-Whitney U-test). 
Table 1: Characteristics of the study subjects

\begin{tabular}{|c|c|c|}
\hline Clinicopathologic features & Number & Percentage $(\%)$ \\
\hline \multicolumn{3}{|l|}{ Age (years) } \\
\hline$<60$ & 62 & 34.4 \\
\hline$\geq 60$ & 118 & 65.6 \\
\hline \multicolumn{3}{|l|}{ Gender } \\
\hline male & 130 & 72.2 \\
\hline female & 50 & 17.8 \\
\hline \multicolumn{3}{|l|}{ Tumour Size (cm) } \\
\hline$<10$ & 156 & 86.7 \\
\hline$\geq 10$ & 24 & 23.3 \\
\hline \multicolumn{3}{|l|}{ Tumour site } \\
\hline cardia & 26 & 14.4 \\
\hline Non-cardia & 154 & 85.6 \\
\hline \multicolumn{3}{|l|}{ Pathological type } \\
\hline adenocarcinoma & 176 & 97.8 \\
\hline undifferentiated carcinoma & 4 & 2.2 \\
\hline \multicolumn{3}{|l|}{ Tumour status } \\
\hline $\mathbf{T} 1+\mathrm{T} 2$ & 24 & 13.4 \\
\hline $\mathbf{T 3}+\mathbf{T} 4$ & 155 & 86.6 \\
\hline \multicolumn{3}{|l|}{ Nodal status } \\
\hline negative & 45 & 25.0 \\
\hline positive & 135 & 75.0 \\
\hline \multicolumn{3}{|l|}{ Metastasis status } \\
\hline M0 & 166 & 92.2 \\
\hline M1 & 14 & 7.8 \\
\hline \multicolumn{3}{|l|}{ Tumour stage } \\
\hline $\mathbf{I}$ & 17 & 9.4 \\
\hline II & 56 & 31.1 \\
\hline III & 92 & 51.1 \\
\hline IV & 14 & 7.8 \\
\hline Follow-up time (months) & $79.2-97.2$ & \\
\hline \multicolumn{3}{|l|}{ Prognosis } \\
\hline alive & 49 & 25.8 \\
\hline dead & 125 & 74.2 \\
\hline patients lived for $\geq 5$ years & 74 & 41.1 \\
\hline patients lived for $<5$ years & 106 & 58.9 \\
\hline
\end{tabular}


Table 2: FGF9 expression and clinicopathological features in patients with gastric adenocarcinoma

\begin{tabular}{|c|c|c|c|c|}
\hline Characteristics & $\begin{array}{c}\text { FGF9 low or } \\
\text { unchanged (\%) }\end{array}$ & FGF9 high (\%) & $\begin{array}{c}\chi^{2} \text { or Fisher's exact } \\
\text { test }\end{array}$ & $P$-value \\
\hline Age( years) & & & 5.634 & 0.018 \\
\hline$<60$ & $38(29.2)$ & $24(48.0)$ & & \\
\hline$\geq 60$ & $92(70.8)$ & $26(52.0)$ & & \\
\hline Gender & & & 2.659 & 0.103 \\
\hline male & $89(68.5)$ & $41(82.0)$ & & \\
\hline female & $41(31.5)$ & $9(18.0)$ & & \\
\hline \multicolumn{5}{|l|}{ Local invasion } \\
\hline $\mathbf{T} 1+\mathbf{T} 2$ & $22(17.1)$ & $2(4.0)$ & & 0.026 \\
\hline $\mathrm{T3}+\mathrm{T} 4$ & 107 (82.9) & $48(96.0)$ & & \\
\hline Site & & & 0.708 & 0.4 \\
\hline gastric cardia & $17(13.1)$ & $9(18.0)$ & & \\
\hline non-cardia & $113(86.9)$ & $41(82.0)$ & & \\
\hline \multicolumn{5}{|l|}{ TNM stage } \\
\hline I + II & $19(14.7)$ & $5(10.0)$ & 0.694 & 0.405 \\
\hline III + IV & $110(85.3)$ & $45(90.0)$ & & \\
\hline Nodal status & & & 2.991 & 0.084 \\
\hline positive & $37(28.5)$ & $8(16.0)$ & & \\
\hline negative & $3(71.5)$ & $42(84.0)$ & & \\
\hline Distant metastasis & & & & 0.760 \\
\hline M0 & $119(96.5)$ & $47(94.0)$ & & \\
\hline M1 & $11(3.5)$ & $3(6.0)$ & & \\
\hline Tumour size(cm) & & & & 0.139 \\
\hline$\geq 10$ & $20(15.5)$ & $4(8.0)$ & & \\
\hline$<10$ & $109(84.5)$ & $46(92.0)$ & & \\
\hline
\end{tabular}

to American Joint Committee on Cancer (AJCC) stage, higher expression of FGF9 remained a significant predictor of poor survival in stage II (30.6 months vs. 64.9 months, $P<0.001, \mathrm{n}=56)$ and stage III GC (29.7 months vs. 58.9 months, $P<0.001, \mathrm{n}=92$ ) (Figure 3).

Multivariate Cox regression analysis identified the following predictors of poor prognosis: tumour status (hazard ratio [HR], 1.77; 95\% confidence interval [CI], $0.73-4.29 ; P=0.204)$, stage (HR, 2.08; 95\% CI, $1.15-$ $3.77 ; P=0.015)$, lymph node metastasis (HR, $1.70 ; 95 \%$ CI, 0.84-3.42; $P=0.139$ ), high FGF9 expression (HR, 2.95; 95\% CI, 1.97-4.41; $P<0.001)$ and tumour size (HR, 2.13; 95\% CI, 1.30-3.47; $P=0.003$ ) (Table 4). Low or unchanged expression of FGF9 compared with neighbouring normal tissue was associated with a better prognosis, while high expression was associated with a poor prognosis in GC.

\section{DISCUSSION}

FGFs are involved in a variety of cellular processes, such as stemness, proliferation, antiapoptosis, drug resistance, and angiogenesis $[12,13]$. Activating mutations or gene amplification of FGFR1, FGFR2, and FGFR3 have been reported in melanoma, endometrial cancer, and bladder cancer, respectively [14-17]. The FGF/FGFR pathway has long attracted attention as a potential therapeutic target and prognostic markers for various diseases, including cancer. 
Table 3: Univariate analysis of survival in patients with GC

\begin{tabular}{|c|c|c|c|}
\hline Variable & Mean survival time month $( \pm \mathrm{SE})$ & 95\% CI(Month) & $P$ \\
\hline Age (years) & & & 0.132 \\
\hline$<60$ & $57.3(4.8)$ & $47.9-66.6$ & \\
\hline$\geq 60$ & $48.9(3.4)$ & $42.3-55.5$ & \\
\hline Gender & & & 0.668 \\
\hline Male & $52.5(3.3)$ & $46.0-59.0$ & \\
\hline Female & $50.5(5.1)$ & $40.6-60.4$ & \\
\hline Tumour site & & & 0.986 \\
\hline Gastric cardia & $53.0(7.4)$ & $38.5-67.4$ & \\
\hline Non-cardia & $51.8(3.0)$ & $45.9-57.7$ & \\
\hline Stage of disease & & & 0.000 \\
\hline I-II & $70.0(4.0)$ & $62.2-77.8$ & \\
\hline III -IV & $39.4(3.4)$ & $32.8-46.1$ & \\
\hline Tumour status (p) & & & 0.008 \\
\hline T1-T2 & $67.5(5.6)$ & $56.5-78.4$ & \\
\hline T3-T4 & $48.5(3.0)$ & $42.6-54.4$ & \\
\hline Node status & & & 0.000 \\
\hline Negative & $72.9(4.8)$ & $63.6-82.3$ & \\
\hline Positive & $44.8(3.1)$ & $38.7-51.0$ & \\
\hline Distant metastasis & & & 0.005 \\
\hline No & $54.0(2.9)$ & $48.2-59.7$ & \\
\hline Yes & $30.2(6.4)$ & $17.6-42.8$ & \\
\hline FGF9 & & & 0.000 \\
\hline High expression & $28.1(3.5)$ & $21.2-35.0$ & \\
\hline Low/unchanged & $55.8(3.5)$ & $48.9-62.7$ & \\
\hline \multicolumn{4}{|l|}{ Tumour size (cm) } \\
\hline$\geq 10$ & $28.4(5.0)$ & $18.5-38.2$ & 0.001 \\
\hline$<10$ & $54.8(3.1)$ & $48.8-60.8$ & \\
\hline
\end{tabular}

FGF9 is involved in various biological processes. For example, FGF9 enhances the phosphorylation of extracellular signal regulated kinase 1/2 (ERK1/2) during osteogenic induction in bone marrow stromal stem cells and dental pulp stem cells [18]. FGF9 may participate in the development of $\mathrm{GC}$ by its autocrine stimulation mode [13]. FGF2, FGF9 and FGF10 can stimulate proliferation, treatment sensitivity, and apoptosis of lung cancer cells in a cell-specific manner [6].

In recent years, activation of FGF/FGFR signals through FGF9 has been reported in several cancers. FGF9 has been shown to be dysregulated in ovarian endometrioid adenocarcinoma [19], hepatocellular carcinoma [20] and prostate carcinoma [21]. The FGF9 serum concentration in lung cancer patients was below the detectable limit by ELISA assay [6]. Leushacke et al. reported that the expression level of FGF9 mRNA was high in a subset of resected non-small cell lung cancer and that FGF9 high expression was negatively correlated with patient survival [10]. Moreover, miRNA-FGF9 pathway is important for lung development and links DICER1 loss contributing to the pathogenesis of pleuropulmonary blastoma [22]. Induction of FGF9 in adult lung resulted in the rapid formation of epithelial tumours that resemble papillary adenocarcinoma [23]. Overexpressing FGF9 in prostate cancer cells augmented the formation of reactive stroma and promoted initiation and progression in prostate cancer cells [24]. 
A previous study showed that FGF9 from cancerassociated fibroblasts may activate invasion and antiapoptosis of gastric cancer cells [25]. In our study, we found that knockdown of FGF9 resulted in reduced growth and induced apoptosis in GC cells. Thus, FGF9 may play an important oncogene function in GC cells and may be a novel target for GC therapy.

In this study, we found that $27.8 \%(50 / 180)$ of GC specimens had high FGF9 expression compared with normal paracancerous tissues. Our previous work found that miR-486-5p can decrease FGF9 protein expression in GC. High expression of miR-486-5p or low expression of FGF9 in a small number of GC patients was linked to longer overall survival [4]. So high expression of FGF9 may predict poor prognosis through aberrant regulation of miR-486-5p in GC patients.

Overexpression of miR-26a can induce apoptosis in GC cells [11], and Deng et al. found that miR-26a suppresses tumour growth and metastasis by targeting

A
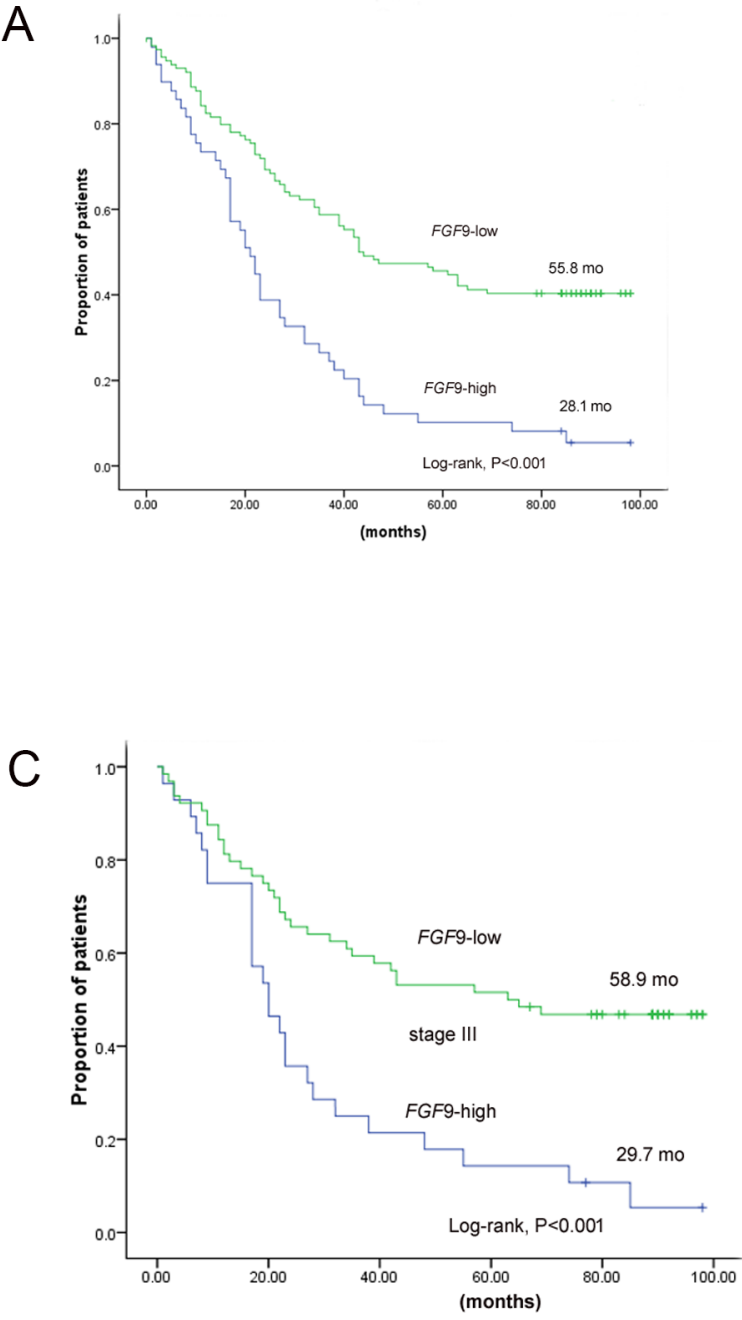

FGF9 in GC [11]. Furthermore, the authors showed that FGF9 overexpression in miR-26a expressing cells could inhibit tumour apoptosis induced by miR-26a. In addition, miR-26a expression inversely correlated with FGF9 protein levels in GC and low expression of miR-26a leads to poor survival in GC patients [11]. Together this suggests that FGF9, as one of the target genes of miR-26a, may play an important role in tumour growth and apoptosis.

Interestingly we found a significant difference in age in patients with low/unchanged levels of FGF9 expression and patients with high expression $\left(\chi^{2}=5.634, P=0.018\right)$, but no significant correlations were found between FGF9 expression levels and other clinicopathological variables, including sex, tumour site, TNM stage, tumour size, nodal status, distant metastasis and depth of tumour invasion. These data indicate that GC patients of older age show a tendency for high expression of FGF9. The underlying mechanism of this phenomenon is unknown.

B

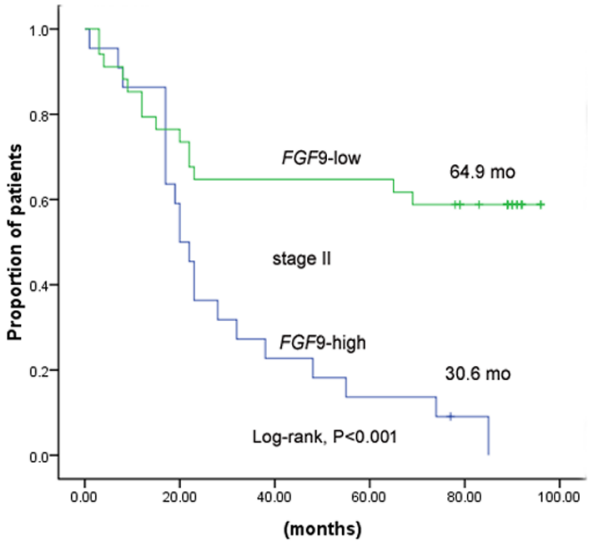

Figure 3: The prognosis of GC patients with high expression of FGF9 and low/unchanged expression of FGF9. A. Kaplan-Meier curves of 163 GC patients according to FGF9 expression. B. Kaplan-Meier curves of 56 GC patients according to FGF9 expression in stage II. C. Kaplan-Meier curves of 92 GC patients according to FGF9 expression in stage III. *P<0.001 (log-rank test). 
Table 4: Multivariate Cox regression analysis of potential prognostic factors for survival in 180 patients with GC

\begin{tabular}{lcccc}
\hline \multirow{2}{*}{ Variables } & \multicolumn{2}{c}{ Univariate analysis } & \multicolumn{2}{c}{ Multivariate analysis } \\
\cline { 2 - 4 } & HR(95\%CI) & $\boldsymbol{P}$-value & HR(95\%CI) & $\boldsymbol{P}$-value \\
\hline Tumour status, T1-T2 vs. T3-T4 & $3.91(1.72-8.91)$ & 0.001 & $1.77(0.73-4.29)$ & 0.204 \\
Stage, I - II vs. III-IV & $2.83(1.88-4.28)$ & 0.000 & $2.08(1.15-3.77)$ & 0.015 \\
LNM, no vs. yes & $2.83(1.88-4.28)$ & 0.000 & $1.70(0.84-3.42)$ & 0.139 \\
Low FGF9 vs. High FGF9 & $2.94(2.01-4.31)$ & 0.000 & $2.95(1.97-4.41)$ & 0.000 \\
Tumour size (cm), <10 vs. $\geq \mathbf{1 0}$ & $2.34(1.45-3.79)$ & 0.002 & $2.13(1.30-3.47)$ & 0.003 \\
Age (years), $\geq \mathbf{6 0}$ vs. $<\mathbf{6 0}$ & $1.35(0.91-2.01)$ & 0.137 & $1.66(1.09-2.53)$ & 0.018 \\
Gender, male vs. female & $0.92(0.61-1.37)$ & 0.671 & $1.04(0.68-1.60)$ & 0.843 \\
Tumour site, gastric cardia vs. non-cardia & $1.51(1.93-2.45)$ & 0.093 & $1.58(0.59-2.62)$ & 0.077 \\
\hline
\end{tabular}

In our research, 180 patients with GC were evaluated for FGF9 expression and 163 were included in the OS analysis. The median follow-up time was as long as 7.1 years (range 6.6-8.1 years). As expected, traditional pathological parameters, such as tumour stage $(P<0.001)$, tumour status $(P=0.008)$, node status $(P<0.001)$, tumour size $(P=$ $0.001)$, and distant metastasis $(P=0.005)$, were significant negative prognostic predictors for OS in patients with GC. Moreover, high FGF9 expression $(P<0.001)$ was also a significant negative prognostic predictor for OS in patients with GC. However, as the prevail of molecular and genotype heterogeneous of GC, patients with the same TNM stage may have distinct prognosis $[3,26]$. So it is urgent to find an ideal tumour maker to evaluate the prognosis in individual GC patient. In our study, after stratification according to AJCC stage, higher expression of FGF9 remained a significant predictor of poor survival in stage II (30.6 months vs. 64.9 months, $P<0.001)$ and stage III GC (29.7 months vs. 58.9 months, $P<0.001)$. Furthermore, multivariate and unvaried Cox analyses indicated a shorter OS with high FGF9 expression (HR, 2.95; 95\% CI, 1.97-4.41, $P<0.001$; and HR, 2.94; 95\% CI, 2.01-4.31, $P<0.001)$. Together these data indicate that high level of FGF9 may be used as an independent indicator for poor prognosis in GC.

Our data suggest that FGF9 could be a novel treatment target for GC. Recently, several FGFR tyrosine kinase inhibitors have been developed for the treatment of GC [9, 12, 27-31]. FGF9 may have the anti-apoptotic function and be used as a potential novel maker for prognosis evaluation in GC. However, the mechanism and the receptor through which FGF9 plays a role in GC initiation and metastasis need to be elucidated in future studies.

\section{MATERIALS AND METHODS}

\section{Cell culture and FGF9 siRNA transfection}

The GC cell lines MGC-803 and SGC-7901 were obtained from the Chinese Academy of Medical Science
(Beijing, China) and maintained at $37^{\circ} \mathrm{C}$ in $5 \% \mathrm{CO}_{2}$ in RPMI-1640 (MGC-803) or DMEM (SGC-7901), respectively, supplemented with $10 \%$ fetal bovine serum (FBS) with penicillin and streptomycin (Gibco BRL, NY, USA). FGF9 and control siRNAs were purchased from GenePharma (Shanghai, China) and the sequences of these siRNAs are as follows: FGF9-homo-1044 SiRNA5'-CUGGAUUUCACUUAGAAAUTT-3', 3'-AUUUCUAAGUGAAAUCCAGTT-5'; FGF9homo-1201 SiRNA 5'-GGAGCUGUAUGGAU CAGAATT-3', 3'-UUCUGAUCCAUACAGCUCCTT-5'; FGF9-homo-1315 siRNA 5'-GCGAUACUAUGUUGC AUUATT-3', 3'-UAAUGCAACAUAGUAUCGCCT-5'; and control 5'-CAGUACUUUUGUGUAGUACAA-3'. Three FGF9 siRNA and controls were synthesized and the inhibition effect was evaluated by immunofluorescence staining. Transfections were performed using Lipofectamine 2000, according to the manufacturer's instructions (Invitrogen, Carlsbad, USA).

\section{Immunofluorescence staining}

The GC cell lines MGC-803 and SGC-7901were cultured in 12-well plates and then transfections were performed using Lipofectamine 2000 for 24 hours. The experimental groups and controls were fixed $4 \%$ poly formaldehyde for $40 \mathrm{~min}$ and were performed 100ul FGF9 antibody (\#ab71395, Abcam Cambridge, UK) overnight at $4^{\circ} \mathrm{C}$. After washing by PBS three times, a goat anti-rabbit IgG-PE was incubate for 1 hours (sc3739, Santa Cruz, USA). After washing by PBS three times, DAPI was stained for nucleus.

\section{Cell proliferation assay}

Cells were plated in 12-well plates at the desired cell concentrations. Cell counts were estimated by trypsinizing the cells and performing counting using a Coulter Counter 
(Beckman Coulter, Fullerton, USA) at the indicated time points in triplicate.

\section{Analysis of apoptosis}

After FGF9 or control siRNA transfection, both attached and floating cells were harvested at different time points and washed with PBS. The fraction of apoptotic cells was determined by nuclear staining and two-colour analysis with Annexin V-PI. Nuclear morphology was assessed with DAPI staining. Briefly, cells were fixed with a solution of $3.7 \%$ formaldehyde, $0.5 \%$ NP-40, and 10 $\mathrm{mg} / \mathrm{mL}$ DAPI and analysed by fluorescence microscopy. Apoptotic cells with condensed chromatin and fragmented nuclei were counted from three fields for each sample. All experiments were carried out in triplicate. For Annexin V-PI staining, the treated cells were stained using an Annexin V-PI assay kit (BioVision Co., Ltd, CA, USA) and quantified and analysed using a BD FACSCalibur flow cytometer (Becton Dickinson).

\section{Colony formation assay}

After FGF9 or control siRNA transfection, cells were trypsinized and seeded in $10-\mathrm{cm}$ dishes $\left(10^{4}\right.$ cells per dish) and cultured in DMEM supplemented with 10\% FBS without anticancer drugs. After 14-16 days, cells were fixed in $3.7 \%$ formaldehyde and stained with $0.25 \%$ crystal violet (AMRESCO) in PBS for 30 minutes. Clones were washed with water and counted. All experiments were carried out in triplicate.

\section{Patients and tissue samples}

Paraffin-embedded tissue samples were collected retrospectively from archival material stored in the Biobank Center at the National Engineering Center for Biochip at Shanghai (Shanghai Outdo Biotech Cop., Ltd, Shanghai, China). Samples from tumour tissue and corresponding neighbouring normal tissue were collected from 180 patients with histologically diagnosed GC who underwent surgical resection between 2006 and 2008.

The following clinicopathological data were obtained from the original pathology reports: age, sex, tumour size, location and invasion, lymph node metastases, grade of differentiation, and tumour stage. Staging of GC was assessed according to the AJCC criteria. The clinical and pathological data for the patients is provided in Table 1. Written informed consent was obtained from all patients, and the protocol was approved by the Ethical Committee of the National Engineering Center for Biochip at Shanghai.

Follow-up times were measured from the date of surgery to the date of death for all $180 \mathrm{GC}$ patients. The last follow-up point was in September 2014, and seventeen patients were out of touch in September 2014, but all had survived for five years in the previous follow up. The median follow-up time was 7.1 years (range 6.68.1 years). Among the 180 patients, 115 died during the follow-up period.

\section{Tissue microarray construction}

Tissue microarrays (TMAs) were constructed using appropriate tissue cores from formalin-fixed and paraffinembedded samples as described previously [32]. Briefly, the appropriate tumour areas and corresponding nontumour gastric samples were selected by pathologists, and a single core (diameter $0.6 \mathrm{~mm}$ ) was taken from each tissue. TMA blocks were constructed using an automated tissue arrayer (Beecher Instruments, Sun Prairie, WI, USA). The array blocks were cut into 5 - $\mu \mathrm{m}$ sections, and the sections were stained with haematoxylin and eosin to verify the presence of tumour cells. In all cases, tissue cores obtained from normal adjacent tissue served as internal controls.

\section{Immunohistochemistry}

Immunohistochemical analysis was performed on 180 GC specimens. All tumour tissues and the surrounding gastric tissues were removed and embedded in paraffin and cut into $4-\mathrm{cm}$-thick sections. These sections were deparaffinized, rehydrated, and incubated in $0.03 \% \mathrm{H}_{2} \mathrm{O}_{2}$ in $95 \%$ methanol at room temperature for 20 min to block endogenous peroxidase activity. Antigen retrieval was performed using water bath pretreatment (Immunosaver; Nisshin EM, Tokyo, Japan) at $98^{\circ} \mathrm{C}$ for $45 \mathrm{~min}$. All sections were incubated for 20 min with normal horse serum to eliminate non-specific staining and incubated with anti-human FGF9 antibody (\#ab71395, Abcam Cambridge, UK) overnight at $4^{\circ} \mathrm{C}$. This step was followed by incubation with the secondary antibody (ImmPRESS Reagent Kit; Vector Laboratories, Burlingame, CA) for $30 \mathrm{~min}$. Slides were then incubated in diaminobenzidine (DAB)/Tris solution (3DAB/Tris) tablets (Muto Pure Chemicals, Tokyo, Japan) diluted in $150 \mathrm{ml}$ of distilled water supplemented with $15 \mu \mathrm{l}$ of $30 \% \mathrm{H}_{2} \mathrm{O}_{2}$. Finally, the slides were counterstained with haematoxylin. The proportion of cells stained and the staining intensity score were assessed by the pathologist as follows: 0, absence of staining; 1, weakly stained; 2, moderately stained; and 3, strongly stained. The total score was calculated by multiplying the proportion score with the intensity score $[4,33,34]$. High expression of FGF9 means that the expression of FGF9 is higher than that of normal tissue adjacent to cancer. Low expression of FGF9 means that the expression of FGF9 is lower than that of normal tissue adjacent to cancer.

\section{Statistical analysis}

Associations between clinicopathological parameters and FGF9 expression were evaluated using 
$\chi^{2}$ tests. When sample numbers in some categorical cells were less than 5, Fisher's exact test was employed. Overall survival was calculated and survival curves were plotted using the Kaplan-Meier method; differences between groups were compared using log-rank tests. Significant variables in univariate models were further analysed by multivariate Cox proportional hazards regression models to identify the independent prognostic values. All analyses were performed using the SPSS software package (SPSS Inc., Chicago, IL, USA, version 17.0). All tests were twosided and $P$ values $<0.05$ were considered statistically significant.

\section{ACKNOWLEDGMENTS}

This study was supported by the National Nature Science Foundation of China $(81573220,81172508)$, the Foundation of the Social Development of Jiangsu Province (BE2012705), the Foundation of Six kinds of talents Summit in Jiangsu Province (WSN-107) the Foundation of China Postdoctoral Studies (M2013541699), the Foundation of Jiangsu Province Postdoctoral Studies (1302149C), and the Foundation for Young Scholar in Yangzhou (YZ2014046).

\section{CONFLICTS OF INTEREST}

Authors declare no competing financial interests.

\section{Author contributions}

CL.Ren. and H.C. developed the concept, designed the experiments, performed the apoptosis experiments, analyzed the results and wrote the manuscript. CX.Hang, DY. Fu, FA.Wang and DX.Wang performed in vitro cell assays. L.M. L.Z and DS.Hang interpreted the results and edited the manuscript.

\section{REFERENCES}

1. Ferlay J, Shin HR, Bray F, Forman D, Mathers C, Parkin DM. Estimates of worldwide burden of cancer in 2008: GLOBOCAN 2008. Int J Cancer. 2010; 127:2893-2917.

2. Network. CGAR. Comprehensive molecular characterization of gastric adenocarcinoma. Nature. 2014; 513:202-209.

3. Wadhwa R, Song S, Lee JS, Yao Y, Wei Q, Ajani JA. Gastric cancer-molecular and clinical dimensions. Nat Rev Clin Oncol. 2013; 10:643-655.

4. Chen H, Ren C, Han C, Wang D, Chen Y, Fu D. Expression and Prognostic Value of miR-486-5p in Patients with Gastric Adenocarcinoma. PLoS One. 2015; 10:e0119384.

5. Turner N, Grose R. Fibroblast growth factor signalling: from development to cancer. Nat Rev Cancer. 2010; 10:116-129.
6. Suzuki T, Yasuda H, Funaishi K, Arai D, Ishioka K, Ohgino K, Tani T, Hamamoto J, Ohashi A, Naoki K, Betsuyaku T, Soejima K. Multiple roles of extracellular fibroblast growth factors in lung cancer cells. Int J Oncol. 2015; 46:423-429.

7. Grose R, Dickson C. Fibroblast growth factor signaling in tumorigenesis. Cytokine Growth Factor Rev. 2005; 16:179-186.

8. Ornitz DM, Itoh N. Fibroblast growth factors. Genome Biol. 2001; 2:Reviews3005.

9. Hong L, Han Y, Liu J, Brain L. Fibroblast growth factor receptor 2: a therapeutic target in gastric cancer. Expert Rev Gastroenterol Hepatol. 2013; 7:759-765.

10. Ohgino K, Soejima K, Yasuda H, Hayashi Y, Hamamoto J, Naoki K, Arai D, Ishioka K, Sato T, Terai H, Ikemura S, Yoda S, Tani T, Kuroda A, Betsuyaku T. Expression of fibroblast growth factor 9 is associated with poor prognosis in patients with resected non-small cell lung cancer. Lung Cancer. 2014; 83:90-96.

11. Deng M, Tang HL, Lu XH, Liu MY, Lu XM, Gu YX, Liu JF, He ZM. miR-26a Suppresses Tumor Growth and Metastasis by Targeting FGF9 in Gastric Cancer. PLoS One. 2013; 8:e72662.

12. Katoh M, Nakagama H. FGF receptors: cancer biology and therapeutics. Med Res Rev. 2014; 34:280-300.

13. Matsumoto-Yoshitomi S, Habashita J, Nomura C, Kuroshima K, Kurokawa T. Autocrine transformation by fibroblast growth factor 9 (FGF-9) and its possible participation in human oncogenesis. Int J Cancer. 1997; 71:442-450.

14. Lin WM, Baker AC, Beroukhim R, Winckler W, Feng W, Marmion JM, Laine E, Greulich H, Tseng H, Gates C, Hodi FS, Dranoff G, Sellers WR, Thomas RK, Meyerson $\mathrm{M}$, Golub TR, et al. Modeling genomic diversity and tumor dependency in malignant melanoma. Cancer Res. 2008; 68:664-673.

15. Cappellen D, De Oliveira C, Ricol D, de Medina S, Bourdin J, Sastre-Garau X, Chopin D, Thiery JP, Radvanyi F. Frequent activating mutations of FGFR3 in human bladder and cervix carcinomas. Nat Genet. 1999; 23:18-20.

16. Spiegelberg C, Giedl J, Gaisa NT, Rogler A, Riener MO, Filbeck T, Burger M, Ruemmele P, Hartmann A, Stoehr R. Frequency of activating mutations in FGFR2 exon 7 in bladder tumors from patients with early-onset and regularonset disease. Int J Clin Exp Pathol. 2014; 7:1708-1713.

17. Cristescu R, Lee J, Nebozhyn M, Kim KM, Ting JC, Wong SS, Liu J, Yue YG. Molecular analysis of gastric cancer identifies subtypes associated with distinct clinical outcomes. Nat Med. 2015; 21:449-456.

18. Lu J, Dai J, Wang X, Zhang M, Zhang P, Sun H, Zhang X, Yu H, Zhang W, Zhang L, Jiang X, Shen SG. Effect of fibroblast growth factor 9 on the osteogenic differentiation of bone marrow stromal stem cells and dental pulp stem cells. Mol Med Rep. 2015; 11:1661-1668. 
19. Hendrix ND, Wu R, Kuick R, Schwartz DR, Fearon ER, Cho KR. Fibroblast growth factor 9 has oncogenic activity and is a downstream target of Wnt signaling in ovarian endometrioid adenocarcinomas. Cancer Res. 2006; 66:1354-1362.

20. Yang H, Fang F, Chang R, Yang L. MicroRNA-140-5p suppresses tumor growth and metastasis by targeting transforming growth factor beta receptor 1 and fibroblast growth factor 9 in hepatocellular carcinoma. Hepatology. 2013; 58:205-217.

21. Li ZG, Mathew P, Yang J, Starbuck MW, Zurita AJ, Liu J, Sikes C, Multani AS, Efstathiou E, Lopez A, Wang J, Fanning TV, Prieto VG, Kundra V, Vazquez ES, Troncoso $\mathrm{P}$, et al. Androgen receptor-negative human prostate cancer cells induce osteogenesis in mice through FGF9-mediated mechanisms. J Clin Invest. 2008; 118:2697-2710.

22. Yin Y, Castro AM, Hoekstra M, Yan TJ, Kanakamedala AC, Dehner LP, Hill DA, Ornitz DM. Fibroblast Growth Factor 9 Regulation by MicroRNAs Controls Lung Development and Links DICER1 Loss to the Pathogenesis of Pleuropulmonary Blastoma. PLoS Genet. 2015; 11:e1005242.

23. Yin Y, Betsuyaku T, Garbow JR, Miao J, Govindan R, Ornitz DM. Rapid induction of lung adenocarcinoma by fibroblast growth factor 9 signaling through FGF receptor 3. Cancer Res. 2013; 73:5730-5741.

24. Huang $Y$, Jin C, Hamana $T$, Liu J, Wang C, An L, McKeehan WL, Wang F. Overexpression of FGF9 in prostate epithelial cells augments reactive stroma formation and promotes prostate cancer progression. Int J Biol Sci. 2015; 11:948-960.

25. Sun C, Fukui H, Hara K, Zhang X, Kitayama Y, Eda H, Tomita T, Oshima T, Kikuchi S, Watari J, Sasako M, Miwa H. FGF9 from cancer-associated fibroblasts is a possible mediator of invasion and anti-apoptosis of gastric cancer cells. BMC Cancer. 2015; 15:333.

26. Ueda T, Volinia S, Okumura H, Shimizu M, Taccioli C, Rossi S, Alder H, Liu CG, Oue N, Yasui W, Yoshida K, Sasaki H, Nomura S, Seto Y, Kaminishi M, Calin GA, et al. Relation between microRNA expression and progression and prognosis of gastric cancer: a microRNA expression analysis. Lancet Oncol. 2010; 11:136-146.

27. Zhao G, Li WY, Chen D, Henry JR, Li HY, Chen Z, ZiaEbrahimi M, Bloem L, Zhai Y, Huss K, Peng SB, McCann DJ. A novel, selective inhibitor of fibroblast growth factor receptors that shows a potent broad spectrum of antitumor activity in several tumor xenograft models. Mol Cancer Ther. 2011; 10:2200-2210.

28. Katoh M. Genetic alterations of FGF receptors: an emerging field in clinical cancer diagnostics and therapeutics. Expert Rev Anticancer Ther. 2010; 10:1375-1379.

29. Bai A, Meetze K, Vo NY, Kollipara S, Mazsa EK, Winston WM, Weiler S, Poling LL, Chen T, Ismail NS, Jiang J, Lerner L, Gyuris J, Weng Z. GP369, an FGFR2-IIIbspecific antibody, exhibits potent antitumor activity against human cancers driven by activated FGFR2 signaling. Cancer Res. 2010; 70:7630-7639.

30. Katoh Y, Katoh M. FGFR2-related pathogenesis and FGFR2-targeted therapeutics (Review). Int J Mol Med. 2009; 23:307-311.

31. Nakamura K, Yashiro M, Matsuoka T, Tendo M, Shimizu T, Miwa A, Hirakawa K. A novel molecular targeting compound as K-samII/FGF-R2 phosphorylation inhibitor, Ki23057, for Scirrhous gastric cancer. Gastroenterology. 2006; 131:1530-1541.

32. He C, Jiang H, Geng S, Sheng H, Shen X, Zhang X, Zhu S, Chen X, Yang C, Gao H. Expression and prognostic value of c-Myc and Fas (CD95/APO1) in patients with pancreatic cancer. Int J Clin Exp Pathol. 2014; 7:742-750.

33. Teishima J, Shoji K, Hayashi T, Miyamoto K, Ohara $\mathrm{S}$, Matsubara A. Relationship between the localization of fibroblast growth factor 9 in prostate cancer cells and postoperative recurrence. Prostate Cancer Prostatic Dis. 2012; 15:8-14.

34. Wojtalla A, Fischer B, Kotelevets N, Mauri FA, Sobek J, Rehrauer H, Wotzkow C, Tschan MP, Seckl MJ, Zangemeister-Wittke U, Arcaro A. Targeting the phosphoinositide 3-kinase p110-alpha isoform impairs cell proliferation, survival, and tumor growth in small cell lung cancer. Clin Cancer Res. 2013; 19:96-105. 